\title{
FOSSMC for AGC of Multi-Area Power System in Open Market Environment
}

\author{
Kurakula Vimala Kumar, V. Ganesh
}

\begin{abstract}
This paper presents a Fractional Order based Second Order Sliding Mode Controller (FOSSMC) for Load Frequency Control (LFC) of Deregulated Multi Area Power System (DMAPS). In this paper a new control strategy have been proposed to improve dynamic response of multi area power system under one possible contract scenario by considering bilateral contracts. This proposed new FOSSMC strategy capable of dealing with frequency deviations for sudden change of load on DISCOs. The advantage of FOSSMC in terms of exhibiting dynamic response compared to group of factional order controllers such as Fractional Order PI(FOPI), Fractional Order Fuzzy Controller(FOFLC) and Fractional Order Sliding Mode Controller(FOSMC) and conventional PI controller.
\end{abstract}

Index Terms: Fractional Order based Second Order Sliding Mode Controller, Load Frequency Control, Deregulated Multi Area Power System, Fractional Order PI Controller, Fractional Order Fuzzy Controller, Fractional Order Sliding Mode Controller

\section{INTRODUCTION}

In power system frequency and voltage are two major control parameters. The control of frequency and voltage put together is called Automatic Generation Control (AGC).LFC is an integral part of AGC. In power system frequency deviation occurs due to mismatch between generation and load demand [1]-[6].In Power System (PS) frequency oscillations minimised by changing tie line power fluctuations. Suddenly load on power system increases, frequency decreases due to generator give-up its kinetic energy to the load [1]-[6]. The LFC is very much complex problem in DPS due to sudden fluctuation of load demand among different DISCOMS [2].The design of load frequency controller for DPS compared to conventional power system due to rapidly varying load demands [3][6]. In [7], [8] presented a modern feedback controller and observer for LFC of competitive electricity market. A robust $\mathrm{H}$ infinity and chattering free SMC presented [9], [10]. In present day scenario there is significant contribution by the researchers with soft computing techniques such as DE optimized fuzzy PID,ANFIS controller tuning with ACS presented[11]-[13].An intelligent controllers presented for LFC[14], [15].An code algorithm with PID, imperialist ,quasi-oppositional harmony search and optimal firefly algorithms were implemented for LFC parameters tuning[12]-[16]. The impact of TCSC,TCPS and SSSC FACTs devices were presented[17], [18].The variation of tuning parameters of FACTs devices of TCSC with quasi-oppositional harmony search algorithm presented[19], [20].The combination of SSSC, SMES for simultaneous LFC

\section{Revised Manuscript Received on July 22, 2019.}

Kurakula Vimala Kumar, Ph.D Scholar, Jawaharlal Nehru Technological University Anantapur, Andhra Pradesh, 515002, India.

V. Ganesh, Professor Dept. of EEE, JNTUA College of Engineering Pulivendula, Pulivendula, Andhra Pradesh 516390, India. control in deregulated electricity market presented[21].The role of AC tie line parallel with HVDC link and controller tuning with HPSO Algorithm presented for LFC[26].A PI controller optimized with PSO,TCPS parameters optimization with PSO to improve dynamic performance presented[27], [28]. A Fuzzy PID tuning with HBMO presented [29].

\section{STRUCTURE OF POWER SYSTEM IN OPEN MARKET ENVIRONMENT}

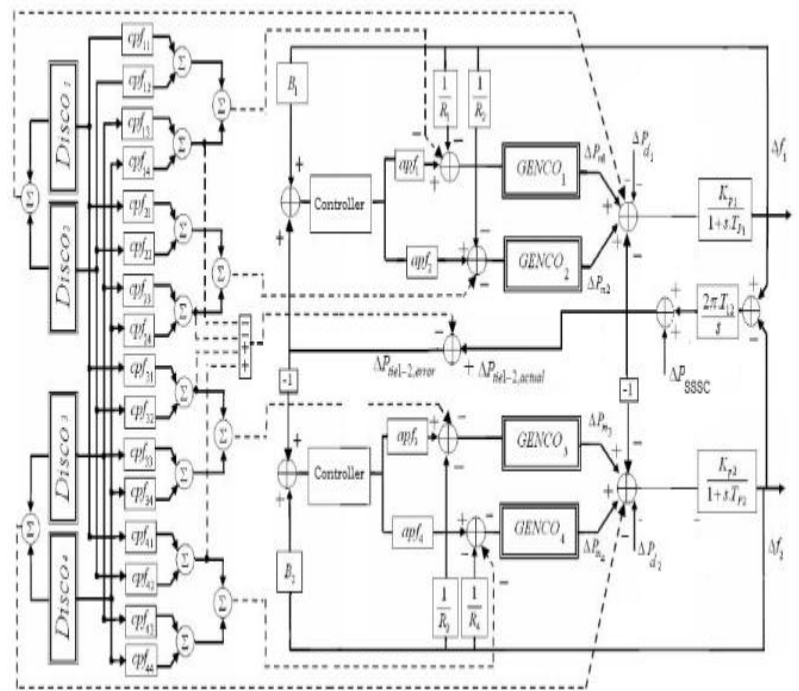

Fig.1. Block diagram of DMAPS with (thermal-thermal)

In the structure of deregulated PS each area consisting of thermal-thermal combination. The modelling of DMAPS presented in [1], [2].

$$
\begin{aligned}
& D P M= {\left[\begin{array}{llll}
c p f_{11} & c p f_{12} & c p f_{13} & c p f_{14} \\
c p f_{21} & c p f_{22} & c p f_{23} & c p f_{24} \\
c p f_{31} & c p f_{32} & c p f_{33} & c p f_{34} \\
c p f_{41} & c p f_{42} & c p f_{43} & c p f_{44}
\end{array}\right] } \\
& \sum c p f_{i j}=1 \\
& \sum_{j=1}^{M} a p f_{i j}=1
\end{aligned}
$$

$M$ is number of GENCOs in each area, ACE participation factors (apf's)', and exchange of tie power flow is a function of Contract Participation Factor (cpf)[7].

$$
\sum_{j=1}^{M} a p f_{i j}=1
$$




$$
\Delta P_{\text {tiel-2error }}=\Delta P_{\text {tie1-2scheduled }}-\Delta P_{\text {tie1-2actual }}
$$

\section{THEORY OF FRACTIONAL CALCULUS}

The non-integer order (Fractional Order) operator $a^{D_{t}^{\alpha}}$ are represented as

$$
a^{D_{t}^{\alpha}} \begin{cases}\frac{d^{\alpha}}{d t^{\alpha}} & \text { for } \alpha>0 \\ 1 & \text { for } \alpha=0 \\ \int_{a}^{t}(d \tau)^{\alpha} & \text { for } \alpha<0\end{cases}
$$

The fractional order derivative originate as defined by R-L

$$
a^{D_{t}^{\alpha}} f(t)=\frac{1}{\Gamma(m-\alpha)}\left(\frac{d}{d t}\right)^{m} \int_{a}^{t} \frac{f(\tau)}{(t-\tau)^{1-(m-\alpha)}} d \tau
$$

The Laplace transform of fractional derivative as suggested by R-L

$$
\left\{0^{D_{t}^{\alpha}} f(t) ; s\right\}=s^{\alpha} F(s)-\sum_{k=0}^{(m-1)} s^{k}\left[o^{D_{t}^{(\alpha-k-1)}} f(t)\right]_{t=0}
$$

Laplace transform of fractional order derivative under initial condition

$$
G(s)=s^{\alpha} \quad \alpha \in R
$$

The fractional Order derivative obtained in terms of filter response

$$
\widehat{G}(s)=K \prod_{k=-N}^{N} \frac{s+\omega_{k}^{\prime}}{s+\omega_{k}}
$$

The poles and zeros are established by the

$$
\begin{gathered}
w_{k}^{\prime}=w_{b .}\left(w_{h} / w_{b}\right)^{(k+N+0.5(1-\alpha)) /(2 N+1)} \\
w_{k}=\omega_{b .}\left(\omega_{h} / \omega_{b}\right)^{(k+N+0.5(1+\alpha)) /(2 N+1)}
\end{gathered}
$$

The order of the filter is $2 \mathrm{~N}+1$ and $w_{b}, \omega_{h}$ are the lower and higher cut-off frequencies[13]

$$
K=w_{h}^{\alpha}
$$

Fractional Order derivative and integral are linear operator as given in equation (13),(14)

$$
\begin{aligned}
& a^{D_{t}^{\alpha}}(f(t)+g(t))=a^{D_{t}^{\alpha}} f(t)+a^{D_{t}^{\alpha}} g(t) \\
& \quad a^{D_{t}^{-\alpha}}(f(t)+g(t))=a^{D_{t}^{-\alpha}} f(t)+a^{D_{t}^{-\alpha}} g(t)
\end{aligned}
$$

\section{A. FOPI Controller for LFC of DMAPS}

The general form of FOPI is $P I^{\lambda}$, where $\lambda$ is a real integer [28]

The FOPI input/output model as (19)

$$
G(s)=K p+\left(\frac{K i}{s^{\lambda}}\right)
$$

The control law of non-integer order controller is represented as $(20)$

$$
u(t)=K p e(t)+K i D^{-\lambda} e(t)
$$

\section{B. Design of Oustaloup Filter}

The approximated transfer function model [56]

$$
K(s)=\left(\frac{1+\frac{b_{s}}{d \omega_{b}}}{1+\frac{d s}{b \omega_{h}}}\right)^{\lambda}
$$

Where $0<\lambda<1, s=j \omega, b>0, d>0$, and

$$
K(s)=\left(\frac{b s}{d \omega_{b}}\right)^{\lambda}\left(1+\frac{-d s^{2}+d}{d s^{2}+b \omega_{h}}\right)^{\lambda}
$$

The Taylor series expansion of input/output model [28],

$$
\begin{gathered}
K(s)=\left(\frac{b s}{d \omega_{b}}\right)^{\lambda}\left(1+\lambda p(s) \frac{\lambda(\lambda-1)}{2} p^{2}(s)+\right. \\
p(s)=\frac{-d s^{2}+d}{d s^{2}+b \omega_{h} s}
\end{gathered}
$$

The fractional order derivative ( $s^{\lambda}$ ) obtained as

$$
\frac{\left(d \omega_{b}\right)^{\lambda} b^{-\lambda}}{\left[1+\lambda p(s)+\frac{\lambda(\lambda-1)}{2} p^{2}(s)+\cdots\right]}\left(\frac{1+\frac{b s}{d \omega_{b}}}{1+\frac{d s}{b \omega_{h}}}\right)^{\lambda}
$$

The fractional derivative $\left(s^{\lambda}\right)$ written as

$$
s^{\lambda} \approx \frac{\left(d \omega_{b}\right)^{\lambda}}{b^{\lambda}(1+\lambda p(s))}\left(\frac{1+\frac{b s}{d \omega_{b}}}{1+\frac{d s}{b \omega_{h}}}\right)^{\lambda}
$$

The non-integer order differential operator is a filter transfer function mode [28]

$$
s^{\lambda} \approx \frac{\left(d \omega_{b}\right)^{\lambda}}{b^{\lambda}(1+\lambda p(s))}\left(\frac{1+\frac{b s}{d \omega_{b}}}{1+\frac{d s}{b \omega_{h}}}\right)^{\lambda}
$$

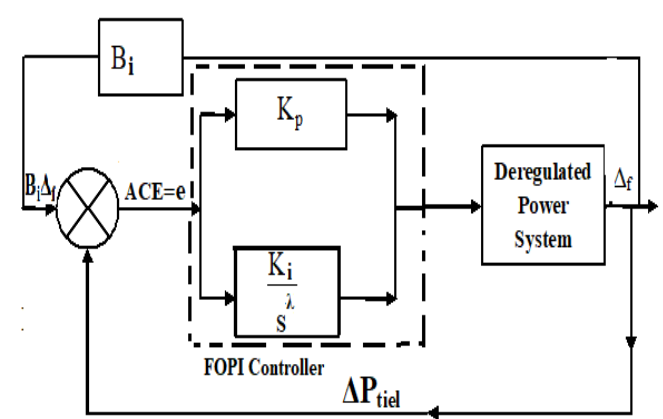

Fig.2. Implementation $y_{4}$ of non-integer order PI(FOPI) controller for LFC of DMAPS.

The fractional order transfer function is stable if poles of the transfer function located at left of the s plane.

$$
d(1-\lambda) s^{2}+a \omega_{h s}+d \lambda=0
$$

The fractional-order part of expression approximated as

$$
k(s)=\lim _{n-\infty} \prod_{K=-N}^{N} \frac{1+s / \omega_{k}^{\prime}}{1+s / \omega_{k}}
$$

The recursive transfer function model [28]

$$
\omega_{K}^{\prime}=\left(\frac{d \omega_{b}}{b}\right)^{\frac{\alpha-2 k}{2 N+1}}, \omega_{b}=\left(\frac{b \omega_{h}}{d}\right)^{\frac{\alpha+2 k}{2 N+1}}
$$

Thus, the continuous rational transfer function model can be obtained as realized in terms of transfer function model of Oustaloup Filter

$$
s^{\lambda} \approx
$$




$$
\left(\frac{d \omega_{h}}{b}\right)^{\lambda}\left(\frac{d s^{2}+b \omega_{h} s}{d(1-\alpha) s^{2}+b \omega_{h} s+d \alpha}\right) \prod_{k=-N}^{N} \frac{s+\omega_{k}^{\prime}}{s+\omega_{k}}
$$

\section{FOFLC FOR LFC OF DEREGULATED POWER SYSTEM}

In the design of FOFLC, the gains of FOPI tuned with a set of Fuzzy rules. The inputs to the FLC controller are ACE and derivative of ACE.

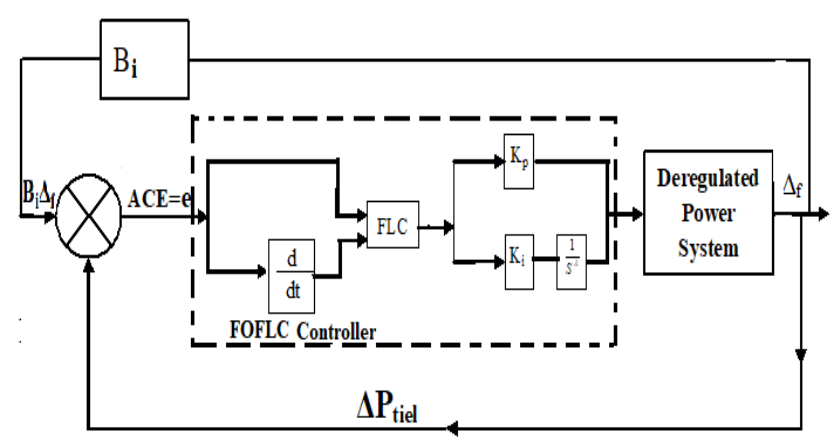

Fig.3 Implementation of FOFLC for control area of DEPS.

Table 1: $K_{p}$ tuning with linguistic rules

\begin{tabular}{|l|l|l|l|l|l|}
\hline e & NB & NM & ZO & PM & PB \\
\hline NB & PB & PB & PM & ZO & ZO \\
\hline NM & PB & PB & PM & ZO & ZO \\
\hline ZO & PM & PM & ZO & NM & NM \\
\hline PM & ZO & ZO & NM & NB & NB \\
\hline PB & ZO & ZO & NM & NB & NB \\
\hline
\end{tabular}

Table 2: $K_{i}$ tuning with linguistic rules.

\begin{tabular}{|l|l|l|l|l|l|}
\hline$\Delta_{-}$e & NB & NM & ZO & PM & PB \\
\hline NB & PB & PB & PM & ZO & ZO \\
\hline NM & PB & PB & PM & ZO & ZO \\
\hline ZO & PM & PM & ZO & NM & NM \\
\hline PM & ZO & ZO & NM & NB & NB \\
\hline PB & ZO & ZO & NM & NB & NB \\
\hline
\end{tabular}

\section{FOSMC MODELING FOR IMPLEMENTATION AS CONTROLLER FOR LFC}

The FOSMC control law obtained by combining fractional calculus with sliding mode,

A. Theory of FOSMC

The FOSMC designed based on sliding surface(S) defined [29]

$S_{1}=D_{t}^{\alpha} e_{1}+\lambda_{1} \cdot\left(e_{1}-z\right)$

$$
\begin{aligned}
& \dot{S}_{1}=D_{t}^{(\alpha-1)} \ddot{e}_{1}+\lambda_{1} \cdot\left(\dot{e}_{1}-\dot{z}\right) \\
& \dot{S}_{1}=D_{t}^{(\alpha-1)}\left(\ddot{x}_{1}-\ddot{x}_{1 d}\right)+\lambda_{1} \cdot\left(\dot{e}_{1}-\dot{z}\right) \\
& \left.\dot{S}_{1}=D_{t}^{(\alpha-1)} f_{1}(x)+b_{1}(x) u+d_{1}-\ddot{x}_{1} d\right)+\lambda_{1} \cdot\left(\dot{e}_{1}-\dot{z}\right)
\end{aligned}
$$

The control law defined as

$$
\begin{array}{r}
u=\frac{-1}{\left(b_{1}-\lambda_{1} \frac{k_{2}}{\Phi_{2}} b_{2}\right)}\left[f_{1}-\ddot{x}_{1 d}-\lambda_{1} \frac{k_{2}}{\Phi_{2}} \cdot\left(f_{2}-\ddot{x}_{3 d}\right)+\right. \\
\left.D_{t}^{(1-\alpha)}\left(\lambda_{1} \cdot \dot{e}_{1}-\lambda_{1} \lambda_{2} \frac{k_{2}}{\Phi_{2}} \cdot \dot{e}_{3}\right)+D_{t}^{(1-\alpha)}\left(k_{1} \cdot \operatorname{sgn}\left(\frac{s_{1}}{\Phi_{1}}\right)\right)\right] \\
-D_{t}^{(\alpha-1)} D_{t}^{(1-\alpha)}\left(\begin{array}{r}
\lambda_{1} \cdot \dot{e}_{1}- \\
\lambda 1 \lambda 2 k 2 \Phi 2 \cdot e 3-D t \alpha-1 D t
\end{array}\right. \\
1-\alpha k 1 \cdot \operatorname{sgns} 1 \Phi 1+\lambda 1 \cdot e 1-\lambda 1 \lambda 2 k 2 \Phi 2 \cdot e 3+D t \\
\alpha-1 d 1-\lambda 1 k 2 \Phi 2 \cdot D t \alpha-1 d 2 \quad(31) \\
\left(\lambda_{1} \cdot \dot{e}_{1}(0)-\lambda_{1} \lambda_{2} \frac{k_{2}}{\Phi_{2}} \cdot \dot{e}_{3}(0)\right)-\lambda_{1} \frac{k_{2}}{\Phi_{2}} \cdot D_{t}^{(\alpha-1)} d_{2} \\
\dot{S}_{1}=-k_{1}\left(\operatorname{sgn}\left(\frac{s_{1}}{\Phi_{1}}\right)\right)+D_{t}^{(\alpha-1)} d_{1}-\lambda_{1} \frac{k_{2}}{\Phi_{2}} \cdot D_{t}^{(\alpha-1)} d_{2} \\
-k_{1}\left(\operatorname{sgn}\left(\frac{s_{1}}{\Phi_{1}}\right)\right)+\Psi_{1}\left(\operatorname{sgn}\left(\frac{s_{1}}{\Phi_{1}}\right)-\lambda_{1} \frac{k_{2}}{\Phi_{2}} \cdot \Psi_{2}\left(s g n\left(\frac{s_{1}}{\Phi_{1}}\right)\right)\right. \\
S_{1} \dot{S}_{1} \leq \Phi_{1} \cdot\left(\Psi_{1}-\lambda_{1} \frac{k_{2}}{\Phi_{2}} \cdot \Psi_{2}-k_{1}\right) \cdot\left(\frac{s_{1}}{\Phi_{1}}\right) \\
S_{1} \dot{S}_{1} \leq \Phi_{1} \cdot\left(\Psi_{1}-\lambda_{1} \frac{k_{2}}{\Phi_{2}} \cdot \Psi_{2}-k_{1}+\xi\right) \cdot\left(\frac{s_{1}}{\Phi_{1}}\right) \\
u=\frac{-1}{\left(b_{1}-\lambda_{1} \frac{k_{2}}{\Phi_{2}} b_{2}\right)}\left[f_{1}-\ddot{x}_{1 d}-\lambda_{1} \frac{k_{2}}{\Phi_{2}} \cdot\left(f_{2}-\ddot{x}_{3 d}\right)+\right. \\
\left.\left.D_{t}^{(1-\alpha)}\left(\lambda_{1} \cdot \dot{e}_{1}-\lambda_{1} \lambda_{2} \frac{k_{2}}{\Phi_{2}} \cdot \dot{e}_{3}\right)+D_{t}^{(1-\alpha)} k_{1} \cdot \operatorname{sat}\left(\frac{s_{1}}{\Phi_{1}}\right)\right)\right](37)
\end{array}
$$

5.2 LFC of DMAPS with FOSMC

In the design of a FOSMC, the ACE is a error signal. The error signal as an input to the controller.

$$
e_{i}=A C E_{i}=B_{i} \Delta f_{\text {ierror }}+\Delta P_{\text {ierror }}, i=1,2,
$$

$e_{i}$ is a state variable $\left(e_{i}=x_{i}\right)$

The sliding surface of $i^{\text {th }}$ control area

$S_{i}=k_{p} e_{i}+k_{d} D^{-\lambda} e_{i}$

The derivative of sliding surface

$$
\begin{aligned}
& S_{i}^{*}=k_{p} e_{i}+k_{d} D^{1-\lambda} e_{i} \\
& S_{i}=k_{p} \dot{x}_{\imath}+k_{d} D^{1-\lambda} x_{i}
\end{aligned}
$$

under steady state Condition ACE is zero

$$
\begin{aligned}
& \dot{x}_{l}=x_{i+1} \\
& k_{p} x_{i+1}+k_{d} D^{1-\lambda} x_{i}=0 \\
& k_{p} x_{i+1}=-k_{d} D^{1-\lambda} x_{i} \\
& \dot{x}_{i}=x_{i+1}=-\frac{k_{d}}{k_{p}} D^{1-\lambda} x_{1} \\
& u=u_{e q}+k \operatorname{sign}(s) \\
& \operatorname{Sgn}(s)=\left\{\begin{array}{c}
-1 \text { if } s<0 ; \\
1 \text { if } s>0 ;
\end{array}\right.
\end{aligned}
$$$$
k_{p} \dot{x}_{\imath}+k_{d} D^{1-\lambda} x_{i}=0
$$

Apply derivative both sides 


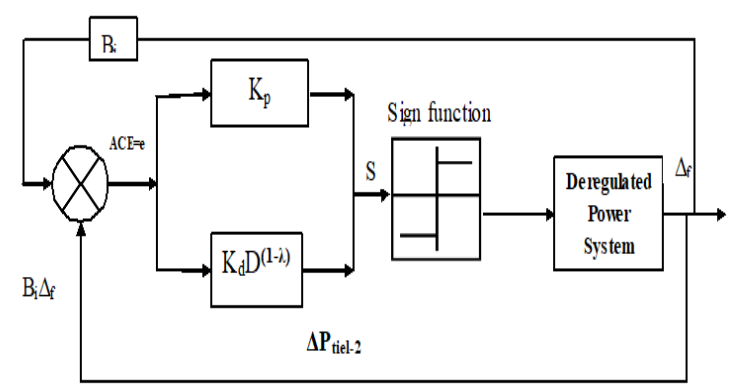

Fig.4. Block diagram model of FOSMC implementation for control area deregulated power system

\section{DESIGN OF FOSSMC FOR LFC OF DMAPS}

The FOSSMC is fast response controller developed based on non-integer calculus [30]. The error dynamics of nonlinear power system is given as

$$
e(t)=\left[e_{1}(t), e_{\mathrm{r}}(t), \ldots . ., e_{\mathrm{n}}(t)\right]=x(t)-x_{\mathrm{r}}(t) .
$$

The fractional-order sliding variable $\sigma(t)$ is function of error

$$
\sigma(t)=I^{(1-\alpha)}\left[e_{n}(t)-\sum_{i=0}^{n-1} c_{i} e_{i}(t)\right]
$$

where the constants $c_{1}, c_{2}, \ldots \ldots, c_{n-1}$ are selected in such a way that all the roots pi of the polynomial

$$
P(s)=s^{(n-1)}+\sum_{i=0}^{n-2} c_{i+1} s^{i}=\prod_{i=1}^{n-1}\left(S-p_{i}\right)
$$

Define the quantity

$$
\xi(t)=e_{n}(t)+\sum_{i=1}^{n-1} c_{i} e_{i}(t) .
$$

$e_{n}(t)$ is given as

$e_{n}(t)=-\sum_{i=1}^{n-1} c_{i} e_{i}(t)+\xi(t)$

Where $\lim _{t \rightarrow 0} \xi(t)=0$

The reduced order equivalent representation is given as

$$
C D^{\alpha} e_{i}=e_{i+1}, \quad i=1,2, \ldots, n-2,
$$

$$
C D^{\alpha} e_{i}=\sum_{i=1}^{n-1} c_{i} e_{i}(t)+\xi(t)
$$

$u(t)$ is the control output of super twisting algorthem

$$
u(t)=u_{1}(t)+u_{1}(t)
$$

$$
\begin{gathered}
\dot{u}_{1}=-\Upsilon \operatorname{sgn}(S) \\
u_{2}=\left\{\begin{array}{lr}
-\lambda\left|s_{0}\right|^{\rho} \operatorname{sgn}(S) & \text { if }|y|>s_{0} \\
-\lambda|y|^{\rho} \operatorname{sgn}(S) & \text { if }|y| \leq s_{0}
\end{array}\right.
\end{gathered}
$$

A. $Y$, and $\boldsymbol{s}_{\mathbf{0}}$ are design parameters.

$\rho$ should be between 0.5 to 1 .

The second control law of $u_{2}(t)$ becomes a linear function of the output sliding function at small departures $\left(|y| \leq s_{0}\right)$.

\section{A. Implementation of FOSSMC for LFC of Deregulated} Power System

The FOSSMC control methodology for multi area deregulated power system implemented. The control methodology implemented in two stages. The ACE is an error signal is an input to the first stage. The output of first stage is input to the second stage while implementation of control law.

$e_{i}=A C E_{i}=B_{i} \Delta f_{\text {ierror }}+\Delta P_{\text {ierror }}, i=1,2$

$e_{i}$ is a state variable $\left(e_{i}=x_{i}\right)$

The sliding surface of $i^{\text {th }}$ control area

$S_{i}=k_{p} e_{i}+k_{d} D^{-\lambda} e_{i}$

The derivative of sliding surface is the output of first stage $S_{i}=k_{p} e_{i}+k_{d} D^{1-\lambda} e_{i}$
$S_{i}=k_{p} \dot{x}_{\imath}+k_{d} D^{1-\lambda} x_{i}$

Sliding surface is input while implementation of second stage of the control methodology, this is known as Second Order Sliding Mode Controller is given as two components

$$
\begin{gathered}
\mathrm{u}(\mathrm{t})=\mathrm{u}_{1}(\mathrm{t})+\mathrm{u}_{2}(\mathrm{t}) \\
\left\{\begin{array}{c}
u_{1}=-\gamma \operatorname{sign}(S), u_{1}(0)=0 \\
u_{2}=-\lambda|\sigma|^{\frac{1}{2}} \operatorname{sign}(S)
\end{array}\right.
\end{gathered}
$$

$\lambda, \gamma$ are the modelling parameters are positive. The implementation of first and second stage combined together a fractional second order sliding mode controller obtained[60,61].

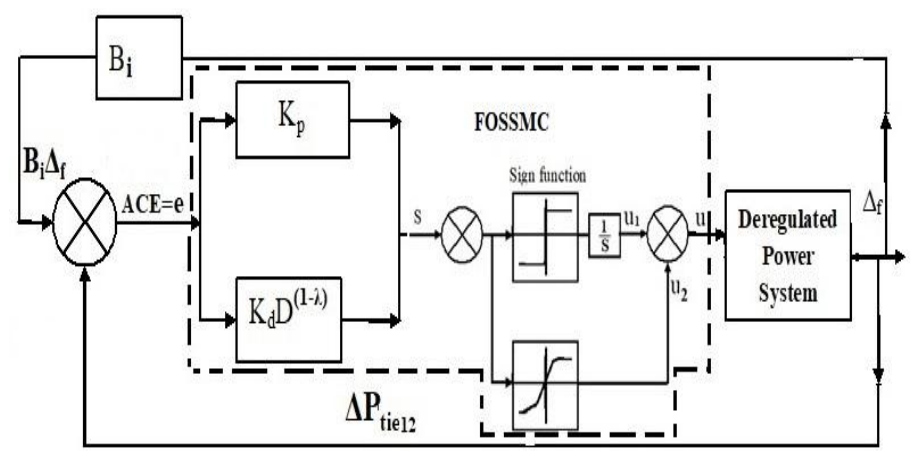

Fig.5. Block diagram model for implementation of FOSSC to LFC of Deregulated Power System

\section{SIMULATION RESULTS}

Simulations are performed under bilateral transaction scenario under various operating condition and larger load demands. DISCOMs draw a mega watt capacity of $0.1 \mathrm{pu}$ MW.

GENCOs participates in AGC based on the following apfs. apfl $=0.6$, apf $2=1-\operatorname{apfl}=0.4$ $\operatorname{apf} 3=0.6, \operatorname{apf} 4=1-\operatorname{apf} 3=0.4$

\section{A. Thermal-Thermal power system with bilateral Transactions}

The DPM matrix for the power transaction between GENCO and TRANSCO is give as

$$
\begin{gathered}
\mathrm{DPM}=\left[\begin{array}{cccc}
0.5 & 0.3 & 0.1 & 0.3 \\
0.1 & 0.2 & 0.6 & 0.2 \\
0.4 & 0.0 & 0.2 & 0.1 \\
0.0 & 0.5 & 0.1 & 0.4
\end{array}\right] \Delta P_{m i}=\sum_{i}^{j} c p f_{i j} \Delta P_{L j} \\
\Delta \mathrm{P}_{\mathrm{m} 1}=0.5(0.1)+0.3(0.1)+0.1(0.1)+0.3(0.1)=0.12 \mathrm{pu} \\
\mathrm{MW} \\
\Delta \mathrm{P}_{\mathrm{m} 2}=0.11 \mathrm{pu} \mathrm{MW} \\
\Delta P_{m 3}=0.07 \mathrm{pu} \mathrm{MW} ; \\
\Delta P_{m 4}=0.1 \text { pu MW; }
\end{gathered}
$$

The dynamic response of two area thermal-thermal power system 


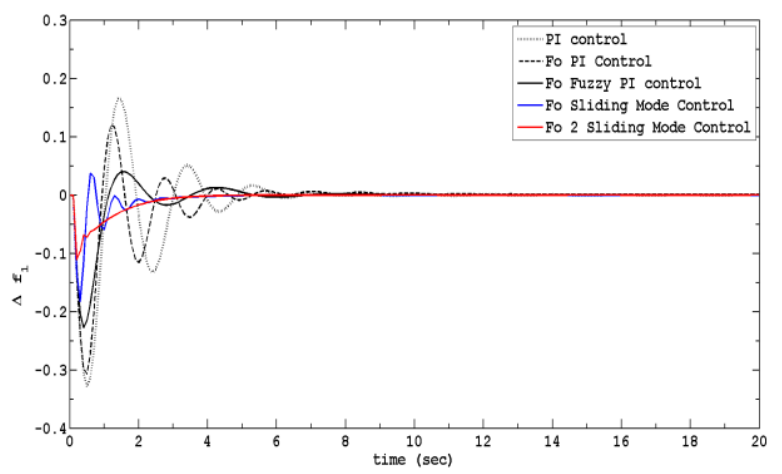

Fig.6. Control Area-1 frequency response with thick red line with FOSSMC

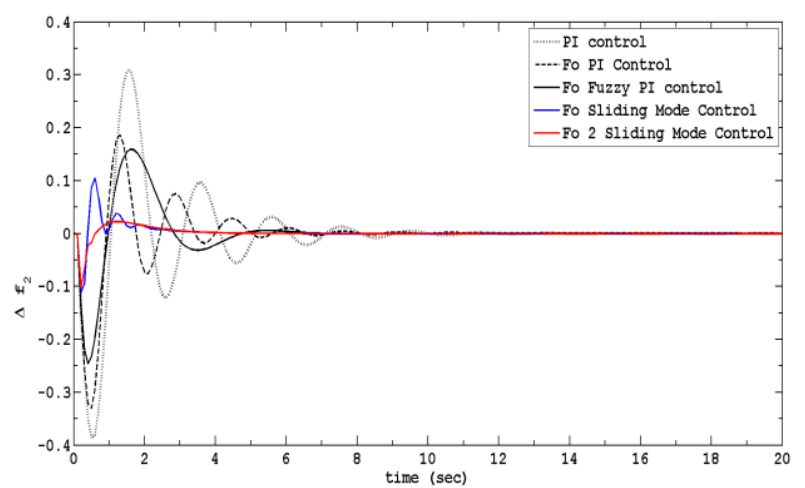

Fig.7. Control Area-2 frequency response with thick red line with FOSSMC

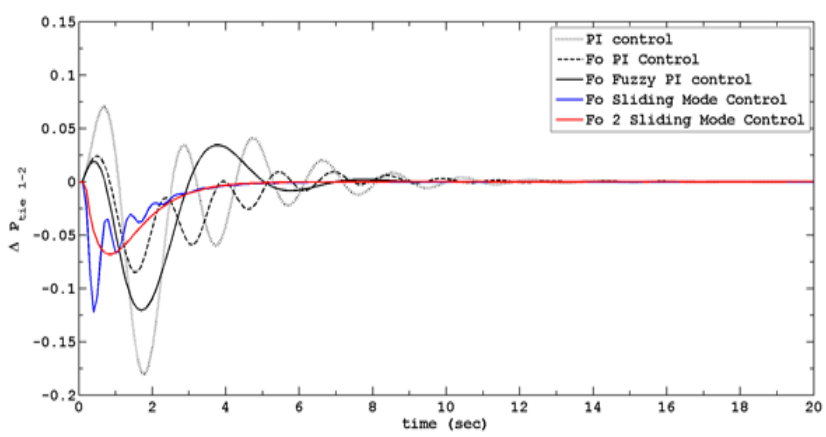

Fig.8. Power deviation in tie line with thick red line with FOSSMC

The performance of the controllers presented in terms of time domain parameters such as overshoot and settling time is given below Table. 3 .

Table.3 Performance of Several Controllers on Various terms

\begin{tabular}{|c|c|c|c|c|}
\hline $\begin{array}{c}\text { Name of } \\
\text { the } \\
\text { controller }\end{array}$ & $\begin{array}{c}\% \\
\text { overshoot } \\
\text { in } \Delta f_{1} \text { of } \\
\text { Control } \\
\text { Area-1 }\end{array}$ & $\begin{array}{c}\% \\
\text { overshoot } \\
\text { in } \Delta f_{2} \text { of } \\
\text { Control } \\
\text { Area-2 }\end{array}$ & $\begin{array}{c}\text { Settling } \\
\text { time of } \\
\Delta f_{1} \text { of } \\
\text { Control } \\
\text { Area-1 }\end{array}$ & $\begin{array}{c}\text { Settling } \\
\text { time of } \\
\Delta f_{2} \text { of } \\
\text { Control } \\
\text { Area-2 }\end{array}$ \\
\hline $\begin{array}{c}\text { PI } \\
\text { Controller }\end{array}$ & $-35 \%$ & $30 \%$ & $\begin{array}{c}12 \\
\text { Sec }\end{array}$ & $\begin{array}{c}14 \\
\text { Sec }\end{array}$ \\
\hline FOPI & $-30 \%$ & $19 \%$ & $6 \mathrm{Sec}$ & $\begin{array}{c}8 \\
\text { Sec }\end{array}$ \\
\hline FOFLC & $-24 \%$ & $15 \%$ & $5.0 \mathrm{Sec}$ & $4 \mathrm{Sec}$ \\
\hline FOSMC & $-18 \%$ & $10 \%$ & $3.0 \mathrm{Sec}$ & $\begin{array}{c}2.5 \\
\mathrm{Sec}\end{array}$ \\
\hline FOSSMC & $-10 \%$ & $01 \%$ & $2.0 \mathrm{Sec}$ & $1.0 \mathrm{Sec}$ \\
\hline
\end{tabular}

\section{CONCLUSION}

This paper presents design of FOSSMC to reduced load frequency oscillations of DMAPS.The performance of the controller compared to normal PI , FOPI,FOFLC and FOFSMC controllers under various operating conditions and larger load distrabances by considereing bilateral contract scenario. The dynamic performance of FOSSMC performance is good by observing diminishing overshoot and settling time and fast dynamic response compared to Fractional Order Sliding Mode Controller(FOSMC), FOFLC,FOPI and conventional PI controller.

\section{REFERENCES}

1. Sadeh J., and Rakhshani E., "Simulation of two-area AGC system in a competitive environment using reduced-order observer method, 5th International Conference on European Electricity Market,2008,PP 1-6.

2. T. Anil Kumar; G. Venu; N. Venkata Ramana, "Load frequency control of multi area power system in deregulated environment with robust Controllers in coordination with frequency controllable HVDC link", International Conference on EnergyEfficient Technologies for Sustainability (ICEETS), Year: 2016, Pages: 473 - 478.

3. Ramesh Kumar Selvaraju, Ganapathy Somaskandan, ACS algorithm tuned ANFIS-based controller for LFC in deregulated environment, Journal of Applied Research and Technology, Volume 15, Issue 2, April 2017, Pages 152-166, ISSN $1665-6423$

4. Rabindra Kumar Sahu, G.T. Chandra Sekhar, Sidhartha Panda DE optimized fuzzy PID controller with derivative filter for LFC of multi source power system in deregulated environment, Ain Shams Engineering Journal, Volume 6, Issue 2, June 2015, Pages 511-530, ISSN 2090-4479.

5. Nagendra Kumar, Vishal Kumar, Barjeev Tyagi, Multi area AGC scheme using imperialist competition algorithm in restructured power system, Applied Soft Computing, Volume 48, November 2016, Pages 160-168

6. Pal, A.K.; Bera, P.; Chakraborty, K. "AGC in two-area deregulated power system using reinforced learning neural network controller", Automation, Control, Energy and Systems (ACES), 2014 First International Conference on, Year: 2014 Pages: 1 - 6.

7. Demiroren A, Sengor NS, Zeynelgil HL "Automatic generation control by using ANN technique" Electrical Power Component System 2001; 29(10):883-96.

8. Javad Morsali, Kazem Zare, Mehrdad Tarafdar Hagh, Performance comparison of TCSC with TCPS and SSSC controllers in AGC of realistic interconnected multi-source power system, Ain Shams Engineering Journal, Volume 7, Issue 1, March 2016, Pages 143-158.

9. Mahendra Nandi, C.K. Shiva, V. Mukherjee,"TCSC based automatic generation control of deregulated power system using quasi-oppositional harmony search algorithm",Engineering Science and Technology, an International Journal, Volume 20 , Issue 4, August 2017, Pages 1380-1395.

10. D. Lakshmi1, A. Peer Fathima and Ranganath Muthu,"Simulation of the Two-Area Deregulated Power System using Particle Swarm Optimization", International Journal on Electrical Engineering and Informatics - Volume 8, Number 1, March 2016, PP 93-107.

11. Shayeghi H, Shayanfar HA, Jalili A LFC-Design-of-a-Deregulated-Power-System with TCPS-Using-PSO. International Journal of Electrical Computer Energetic Electronc and Communication Engineering 2009; Vol:3 (No:4). pp 691-699.

12. Abedinia O., Naderi M S. and Ghasemi., "A Robust LFC in deregulated environment: Fuzzy PID using HBMO", 10th International Conference on Environment and Electrical Engineering (EEEIC), 2011, PP 1-4.

13. Rabindra Kumar Sahu, Sidhartha Panda, Umesh Kumar Rout, DE optimized parallel 2-DOF PID controller for load frequency control of power system with governor 
dead-band nonlinearity, International Journal of Electrical Power \& Energy Systems, Volume 49, July 2013, Pages 19-33, ISSN 0142-0615.

14. Puja Dash, Lalit Chandra Saikia, Nidul Sinha, "Comparison of performances of several FACTS devices using Cuckoo search algorithm optimized 2DOF controllers in multi-area AGC", International Journal of Electrical Power \& Energy Systems, Volume 65, February 2015, Pages 316-324.

15. Rabindra Kumar Sahu, Sidhartha Panda, Saroj Padhan, A novel hybrid gravitational search and pattern search algorithm for load frequency control of nonlinear power system, Applied Soft Computing, Volume 29, April 2015, Pages 310-327, ISSN 1568-4946.

16. Puja Dash, Lalit Chandra Saikia, Nidul Sinha, Flower Pollination Algorithm Optimized PI-PD Cascade Controller in Automatic Generation Control of a Multi-area Power System, International Journal of Electrical Power \& Energy Systems, Volume 82, November 2016, Pages 19-28, ISSN 0142-0615.

17. Dipayan Guha, Provas Kumar Roy, Subrata Banerjee, Load frequency control of large scale power system using quasi-oppositional grey wolf optimization algorithm, Engineering Science and Technology, an International Journal, Volume 19, Issue 4, December 2016, Pages 1693-1713, ISSN 2215-0986.

18. K. P. S. Parmar, S. Majhi and D. P. Kothari, "Optimal Load Frequency Control of an Interconnected Power System," International Journal of Electrical and Instrumentation Engineering, Vol. 1, No. 1, pp. 1-5, January 2011.

19. Ibraheem and P. Kumar, "A Novel Approach to the Matrix Riccati Equation Solution: An Application to Optimal Control of Interconnected Power Systems," Electric Power Components and Systems, Vol. 32, No. 1, pp. 33-52, 2004.

20. T. Anil Kumar, Dr. N. V. Ramana, "Design of Optimal Sliding mode Controller for Load Frequency Control in Multi-area Deregulated Thermal System", International Conference on Emerging Trends in Electrical Engineering and Energy Management (ICETEEEM-2012), ICETEEEM-2012 Proceedings, PS-13, Page No: 64-71.

21. Farzin Piltan, Ali Hosainpour, Ebrahim Mazlomian, Mohammad Shamsodini, Mohammad HosseinYarmahmoudi Online Tuning Chattering Free Sliding Mode Fuzzy Control Design: Lyapunov Approach, International Journal of Robotics and Automation (IJRA), Volume (3),Issue (3) : 2012

22. A.shingame, T. Furukawa, S. Kawamoto, T. Taniguchi, Sliding mode controller design based on fuzzy inference for nonlinear systems, IEEE Trans. Ind. Electron. 40 (1993) 64-70.[55]

23. Hidekazu K., Yuya S. and Shinichi I., "A Load frequency control design using sliding mode controller theory with VSS observer 2009.

24. S. Baghya Shree, N. Kamaraj, Hybrid Neuro Fuzzy approach for automatic generation control in restructured power system, International Journal of Electrical Power \& Energy Systems, Volume 74, January 2016, Pages 274-285, ISSN 0142-0615.

25. Sanjoy Debbarma, Member, IEEE, and Arunima Dutta "Utilizing Electric Vehicles for LFC in Restructured Power Systems Using Fractional Order Controller", IEEE Transactions On Smart Grid, Year: 2017 , Volume: 8 , Issue:6,Pages: $2554-$ 2564 .

26. 1.Shivam Jain and Yogesh V. Hote, " Design of fractional PID for Load frequency control via Internal model control and Big bang Big crunch optimization"Preprints of the 3rd IFAC Conference on Advances in Proportional-Integral-Derivative Control, Ghent, Belgium, May 9-11, 2018, pages 610-615.

27. T.Dinesh,PalleJayabharath Reddy and Thalluru Anil Kumar, " A Coordinated V2GControl For LFC Of Multi Area Power System With HVDC Link In Deregulated Environment", International Journal of Pure and Applied Mathematics, Volume 120 No. 6 2018, pages.567-586,ISSN: 1314-3395

28. Swati Sondhi, Yogesh V. Hote,S. Sondhi, Y.V. Hote ," Fractional order PID controller for load frequency control", Energy Conversion and Management 85 (2014) 343-353.

29. A.Jakovljevi, A. Pisano1,M. R. Rapai and E. Usai1," On the sliding-mode control of fractional-order nonlinearuncertaindynamics", International Journal of Robust and nonlinear control,Int. J. Robust Nonlinear Control (2015),Published online in Wiley Online Library (wileyonlinelibrary.com). DOI: 10.1002/rnc.3337.

30. Abdelali Boughaba, Mabrouk Chaabane And Said Benaggoune,"Robust Sensorless Control Of BLDC Motor Using Second Derivative Function of The Sum Of Terminal Voltages", Serbian Journal of Electrical Engineering Vol. 10, No. 2, June 2013, 275-291,PP-275-291. 